\title{
Изменения нейротрофического обеспечения сетчатки с возрастом и при развитии возрастной макулярной дегенерации
}

\author{
Телегина Д.В., Кожевникова О.С., Колосова Н.Г.
}

Федеральное государственное бюджетное научное учреждение «Федеральный исследовательский центр Институт цитологии и генетики Сибирского отделения Российской академии наук».

630090, Новосибирск, проспект Академика Лаврентьева, д. 10

Возраст - ведущий фактор риска возрастной макулярной дегенерации (ВМД), комплексного многофакторного нейродегенеративного заболевания, встречаемость которого растёт на фоне постарения населения. Несмотря на интенсивные исследования патогенеза ВМД, имеющаяся информация об изменениях нейротрофического обеспечения сетчатки при старении и развитии ВМД ограничена. В то же время очевидно, что патогенез ВМД связан С характерными для старения нарушениями нейротрофического обеспечения сетчатки, которые усугубляются при развитии нейродегенеративных прочессов. Доказан нейропротекторный потенциал экзогенных нейротрофинов, однако для разработки эффективных препаратов на их основе необходимо решить вопрос о путях их эффективной доставки в сетчатку и поддержания в ней оптимального баланса нейротрофинов, определить который помогут дополнительные фундаментальные исследования.

Ключевые слова: старение; сетчатка; возрастная макулярная дегенерачия; нейротрофины.

Для цитирования: Телегина Д.В., Кожевникова О.С., Колосова Н.Г. Изменения нейротрофического обеспечения сетчатки с возрастом и при развитии возрастной макулярной дегенерации. Патогенез. 2019; 17(4): 14-20.

DOI: $10.25557 / 2310-0435.2019 .04 .14-20$

Для корреспонденции: Колосова Наталия Гориславовна, e-mail: kolosova@bionet.nsc.ru Финансирование. Работа поддержана бюджетным проектом № 0324-2018-0019. Конфликт интересов. Авторы заявляют об отсутствии конфликта интересов. Поступила: 30.08 .2019

\section{Alterations of retinal neurotrophic supply with age and during development of age-related macular degeneration \\ Telegina D.V., Kozhevnikova O.S., Kolosova N.G.}

Institute of Cytology and Genetics, Siberian Branch of Russian Academy of Sciences,

Prospekt Akademika Lavrentjeva 10, Novosibirsk 630090, Russian Federation

Age-related macular degeneration (AMD) is becoming the primary cause of irreversible vision loss in patients aged 60 years or older. AMD is a complex and multi-factor neurodegenerative disease, which leads to death of photoreceptor cells, underlying retinal pigment epithelium cells, and alteration of the macular part of the Bruch's membrane and choriocapillaries, all culminating in the loss of central vision. Age-related disruption of retinal neurotrophic supply has been suggested to play a significant role in the development of AMD similarly to other neurodegenerative diseases. Neurotrophic factors participate in maintenance of structural integrity and functional activity of neurons during their development and in maturity to promote survival and regeneration during aging and age-related diseases. An optimal balance of neurotrophins ensures a proper interaction of neurons, microglia, and Müller cells. Notably, an amazingly broad range of critical functions of neurotrophins is achieved through various mechanisms of signal transduction. The neuroprotective potential of neurotrophins has been demonstrated in animals; however, development of effective drugs for AMD requires solving the issues of efficient neurotrophins delivery to the retina and maintenance of their optimal balance. Future basic studies will specify this balance.

Key words: aging; retina; age-related macular degeneration; neurotrophins.

For citation: Telegina D.V., Kozhevnikova O.S., Kolosova N.G. [Alterations of retinal neurotrophic supply with age and during development of age-related macular degeneration]. Patogenez. [Pathogenesis]. 2019; 17(4): 14-20 (in Russian)

DOI: $10.25557 / 2310-0435.2019 .04 .14-20$

For correspondence: Kolosova Nataliya Gorislavovna, e-mail: kolosova@bionet.nsc.ru Funding. The work was supported by the budget project \#0324-2018-0019.

Conflict of interest. The authors declare no conflict of interest.

Received: 30.08 .2019 
Возраст является ведущим фактором риска возрастной макулярной дегенерации (ВМД) - нейродегенеративного заболевания сетчатки, которое становится основной причиной потери зрения людьми старше 60 лет в развитых странах. По прогнозам, в результате постарения населения число страдающих ВМД людей с 64 миллионов в 2014 году к 2040 году возрастет до 288 миллионов [1]. ВМД - комплексное многофакторное заболевание, которое приводит к необратимому отмиранию фоторецепторов, подлежащих клеток ретинального пигментного эпителия (РПЭ), изменениям мембраны Бруха и хориокапилляров в области макулы, к потере центрального зрения [2, 3].

Риск развития и скорость прогрессии ВМД, а также реакция на терапию зависят от взаимодействия множества генетических и средовых факторов. Выделяют «сухую» и «влажную» формы заболевания. Около 90\% случаев приходится на «сухую» атрофическую форму ВМД. «Влажная» (экссудативная) форма развивается у 10\% больных ВМД и характеризуется разрастанием новообразованных сосудов через дефекты мембраны Бруха под пигментный эпителий сетчатки или под нейроэпителий. Повышенная проницаемость новообразованных сосудов приводит к отеку сетчатки, выделению экссудата и кровоизлияниям в стекловидное тело и сетчатку, что в итоге и приводит к потере зрения [4, 5]. Благодаря использованию антиангиогенной терапии (ингибиторов эндотелиального фактора роста сосудов VEGF) достигнуты впечатляющие успехи в лечении «влажной» ВМД.

При сухой форме заболевания в макулярной области диагностируются друзы, происходит перераспределение пигмента, появляются дефекты пигментного эпителия и хориокапиллярного слоя, происходит гибель фоторецепторов на фоне атрофии и гибели клеток РПЭ [6]. Эффективных способов лечения и профилактики «сухой» формы ВМД не существует, что связано с неполнотой знаний о её патогенезе [7].

Характерные для физиологического старения структурно-функциональные изменения сетчатки потеря меланиновых гранул клетками РПЭ, нарушение их базальной складчатости и атрофия микроворсинок, увеличение количества и повышение плотности липофусциновых гранул, формирование друз, уплотнение мембраны Бруха, склероз стенок хориокапилляров и сужение их просвета - аналогичны тем, что происходят на ранних стадиях ВМД и лежат в основе патогенеза заболевания, но не всегда приводят к его развитию $[8,9]$. Очевидно, что существенный вклад в развитие ВМД, как и других нейродегенеративных заболеваний, могут вносить нарушения с возрастом нейротрофического обеспечения сетчатки [10].

Нейротрофические факторы играют важную роль в поддержании целостности и функций нейронов в процессе развития и во взрослом организме, способствуют выживанию и регенерации нейронов во время старения и при возрастных заболеваниях. Их оптимальный баланс обеспечивает взаимодействие между нейрона- ми, микроглией и клетками Мюллера, при этом удивительно широкий диапазон критически важных функций нейротрофинов достигается с помощью разнообразных сигнальных механизмов. Закономерно, что в литературе активно обсуждается перспективность использования нейротрофических факторов для лечения «сухой» формы ВМД [11]. Однако для их успешного использования необходима информация о характере изменений экспрессии нейротрофинов в стареющей сетчатке, которая крайне ограничена, а данные о состоянии нейротрофического обеспечения сетчатки в динамике развития ВМД практически отсутствуют.

\section{Нейротрофические факторы и их рецепторы}

Нейротрофические факторы - это семейство факторов роста, которые принимают участие в регуляции роста, созревания и дифференцировки клеток ЦНС. Во взрослом организме нейротрофические факторы участвуют в регуляции синаптической пластичности и в поддержании жизнеспособности нейронов, в том числе в сетчатке, а также вовлечены в процессы адаптации к внешним воздействиям [12]. Большинство нейротрофических факторов относят к одному из трёх семейств: семейству нейротрофинов (BDNF, NGF, NT-3, NT-4/5 и др.), глиальных нейротрофических факторов (GDNF и др.) и нейропоэтических цитокинов (CNTF и др.).

Нейротрофические факторы, принадлежащие ко второму и третьему семействам (в частности, CNTF и GDNF) локализуются в основном в клетках Мюллера (GDNF) [13], а также в макроглии, ганглионарных нейронах и РПЭ (CNTF) [14]. CNTF участвует в развитии нервной системы, стимулируя экспрессию специфичных генов в нейронах, в особенности моторных [15], a GDNF способствует поддержанию жизнеспособности дофаминергических нейронов. При этом исследования показывают, что GDNF способен усиливать экспрессию других нейротрофических факторов, таких как BDNF, bFGF и GDNF в клетках Мюллера [16].

Нейротрофические факторы, относящиеся к первому семейству (собственно нейротрофины), представляют собой нековалентно-ассоциированные белковые гомодимеры третичной структуры, имеющие в своём составе цистеиновый узел - структуру из $\beta$-слоёв, закрученных друг вокруг друга и связанных тремя дисульфидными мостиками между остатками цистеина. У млекопитающих подробно исследованы четыре типа нейротрофинов: фактор роста нервов (NGF), нейротрофический фактор мозга (BDNF), нейротрофин 3 (NT-3) и нейротрофин 4 (NT4/5). Нейротрофины синтезируются на шероховатом ЭПР в виде незрелой проформы (proNTs) [3]. Проформы нейротрофинов секретируются в неизменённом виде либо подвергаются внутриклеточному или внеклеточному процессингу с превращением в зрелые формы (mNTs). Зрелые формы нейротрофинов оказывают аутокринное или 
паракринное воздействие на клетки-мишени, способствуя росту аксонов нервных клеток по градиенту концентрации и образованию новых синапсов, повышают выживаемость нейронов [17, 18]. В центральной нервной системе фактор роста нервов NGF, связываясь со своим рецептором TrkA, стимулирует нейрональную пластичность и регенерацию аксонов, при этом одним из основных его эффектов является ретроградный транспорт молекул по аксону - от синаптической мишени-рецептора до ядра соответствующего нейрона. Также различные формы нейротрофинов участвуют в процессах ноцицепции [19] и защищают клетки при развитии ряда нейродегенеративных заболеваний [10].

Существует два вида рецепторов, с которыми могут связываться нейротрофины - тирозинкиназные рецепторы и рецептор фактора роста нервов (NGFR, $\left.\mathrm{p} 75^{\mathrm{NTR}}\right)$. Зрелые формы нейротрофинов обладают аффинностью к различным видам тирозинкиназных рецепторов - TrkA, TrkB, TrkC, и опосредуют эффекты, способствующие поддержанию жизнеспособности клеток. TrkA связывает преимущественно NGF, TrkB - BDNF и NT-4/5, а TrkC - NT-3 [20]. Связывание нейротрофина со своим рецептором приводит к аутофосфорилированию внутриклеточного домена рецептора и активации одного из трёх основных сигнальных путей: каскада митоген-активируемых протеинкиназ (ERK/MAРК путь), фосфолипазы C-g (PLC-g путь) или фосфатидилинозитол 3-киназы (PI3K/Akt/mTOR путь) [21, 22], которые играют важную роль в выживании нейронов и регенерации аксонов после повреждения периферических нервов, регулируют пролиферацию, дифференцировку, выживание и апоптоз клеток.

Фосфолипаза C-g гидролизует фосфатидилинозитол $(4,5)$ бифосфат в диацилглицерол и инози-

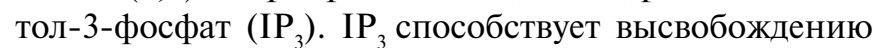
внутриклеточных ионов $\mathrm{Ca}^{2+}$, который в свою очередь активирует кальций-кальмодулин зависимые протеинкиназы [20]. Ионы $\mathrm{Ca}^{2+}$ и диацилглицерол активируют протеинкиназу C, запуская сигнальный путь Erk [20, 23], что приводит к усилению клеточной дифференцировки, ретроградного транспорта и роста аксонов. Другим эффектом активации фосфолипазы C-g является образование белкового комплекса TrkB и PSD95 (белка постсинаптической плотности 95) и усиление трансляции белка CREB, регулирующего транскрипцию генов $c$-fos и $b d n f[17,24]$.

Фосфорилирование Trk у остатка тирозина, ближайшего к трансмембранному домену, Y490 в TrkA или Y515 в TrkB, создает сайт связывания для Shc [25], что приводит к активации фосфатидилинозитол 3-киназы (PI3К), которая повышает внутриклеточный уровень серин/треонин-специфической протеинкиназы (Akt). Встраиваясь в плазматическую мембрану, Akt активируется, что приводит к увеличению синтеза участвующих в дифференцировке нервных клеток белков за счёт активации комплекса mTOR [20, 25], к усилению роста

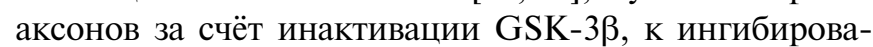

нию проапоптотического белка Ваd и активации антиапоптотического пути NFxB за счёт снижения экспрессии транскрипционного фактора FKHRL1 [26].

Сигнальный путь митоген-активируемых протеинкиназ (МАРК/ERK) способен активироваться двумя различными путями, при этом в обоих случаях в основе активации лежит фосфорилирование Trk рецепторов [27, 28]. В первом случае она связана с формированием комплекса из белков Grb2 и SOS, которое стимулирует активацию Ras-внеклеточной сигнал-регулируемой киназы (Erk) через каскад реакций c-Raf/ MEK/Erk. Второй путь требует наличия белка ARMS/ Kidins220, который рекрутирует адаптерный белок Crk [29]. Связывание с Crk активирует фактор C3G и инициирует Rap1/Raf-зависимое проведение сигнала по пути MEK/Erk. Активация этого пути любым из двух способов ведёт к локальному росту аксона, CREB-опосредованному усилению трансляции и пролиферативной активности [20, 27, 29].

Все зрелые нейротрофины связываются с трансмембранным рецептором $\mathrm{p} 75^{\mathrm{NTR}}$, принадлежащим к суперсемейству рецепторов фактора некроза опухоли TNF. Рецептор p75 ${ }^{\mathrm{NTR}}$ является представителем подкласса этого суперсемейства, известного как рецепторы смерти, поскольку содержит цитоплазматический домен смерти, который обеспечивает ключевые сигнальные эффекты [30]. Обладая низкой аффинностью к зрелым формам нейротрофинов NGF и BDNF, тем не менее, p75 ${ }^{\mathrm{NTR}}$ способен связываться с ними и диссоциировать с высокой скоростью. При этом р75 ${ }^{\mathrm{NTR}}$ в комплексе с Trk рецепторами повышает селективность и аффинность последних к mNTs, увеличивая чувствительность нейронов к более низким концентрациям зрелых форм нейротрофинов [10, 21, 31]. Связывание проформ нейротрофинов с р75 ${ }^{\mathrm{NTR}}$ приводит к активации белков семейства JNK, что в конечном итоге способствует запуску апоптоза в клетке. Показано, что в период развития нервной системы взаимодействие proBDNF c p75 ${ }^{\mathrm{NTR}}$ приводит к гибели нервных клеток, не образовавших синаптические контакты [10, 30]. Проформы нейротрофинов могут также связываться с комплексом из р75 ${ }^{\mathrm{NTR}}$ рецептора и белка сортилина, запуская апоптоз [30, 32].

В сетчатке экспрессия про- и зрелой формы NGF выявляется в нейронах ганглионарного слоя, амакриновых клетках, внешних сегментах фоторецепторов и клетках РПЭ [33], при этом наибольшие концентрации зрелой формы белка обнаружены в ганглионарных нейронах [34] клетках Мюллера [35]. Белок рецептора TrkA синтезируется в клетках РПЭ, ядрах и внешних сегментах фоторецепторах, биполярных, Мюллеровых, амакриновых и ганглионарных клетках, а также астроцитах. В ряде исследований показано иммуноокрашивание NGF во внешнем ядерном слое, содержащем ядра фоторецепторов, а также и в их внешних сегментах (рис. 1) [33]. В период эмбрионального развития proBDNF и proNGF в большом количестве экспрессируют клетки 
ганглионарного слоя сетчатки, что обусловлено высокой активностью процессов апоптоза в развивающейся нервной системе [36, 37]. В зрелой сетчатке проформы белков proBDNF и proNGF в основном синтезируются и секретируются клетками микроглии, активированными в результате повреждения сетчатки [37, 38].

Нейротрофический фактор мозга BDNF оказывает воздействие на многие типы нейронов, в том числе и нейроны сетчатки, и является одним из наиболее изученных нейротрофических факторов. Показано, что во время развития ЦНС он участвует в дифференцировке нейронов, созревании, выживании и формировании синапсов [39, 40]. Во взрослом организме BDNF оказывает защитное действие на нейроны, предупреждая развитие апоптоза нервных клеток. Зрелые и проформы BDNF экспрессируются в различных типах амакриновых клеток, в изолированных культурах клеток Мюллера и телах ганглионарных нейронов сетчатки [33]. В период эмбрионального развития BDNF экспрессируется в клетках РПЭ и на участке недифференцированных клеток, которые позже образуют слой ганглионарных нейронов [41].

Различные формы TrkB рецепторов к BDNF экспрессируются в клетках Мюллера и биполярных клет- ках [42], ганглионарных нейронах [43]. На данный момент наличие рецепторов к нейротрофину BDNF в фоторецепторах остаётся под вопросом, так как данные исследований противоречивы. Рецептор нейротрофинов $\mathrm{p} 75^{\mathrm{NTR}}$ экспрессируется во внешних сегментах фоторецепторов и клетках Мюллера [33] (рис. 1).

Таким образом, нейротрофическая поддержка с участием NGF и BDNF является необходимым условием для выживания нейронов сетчатки. В последние годы растёт количество данных о вкладе нарушения нейротрофического обеспечения в патогенез ВМД, a также других нейродегенеративных заболеваний. Предпринимаются попытки разработки терапии, основанной на интравитеральном введении или использования вирусных векторов для доставки нейротрофинов к месту назначения.

\section{Изменения экспрессии нейротрофинов в сетчатке при старении и их вклад в развитие нейродегенеративных процессов}

Многочисленными исследованиями показано, что характерное для старения нарушение сигнальных путей нейротрофических факторов, баланса проней-

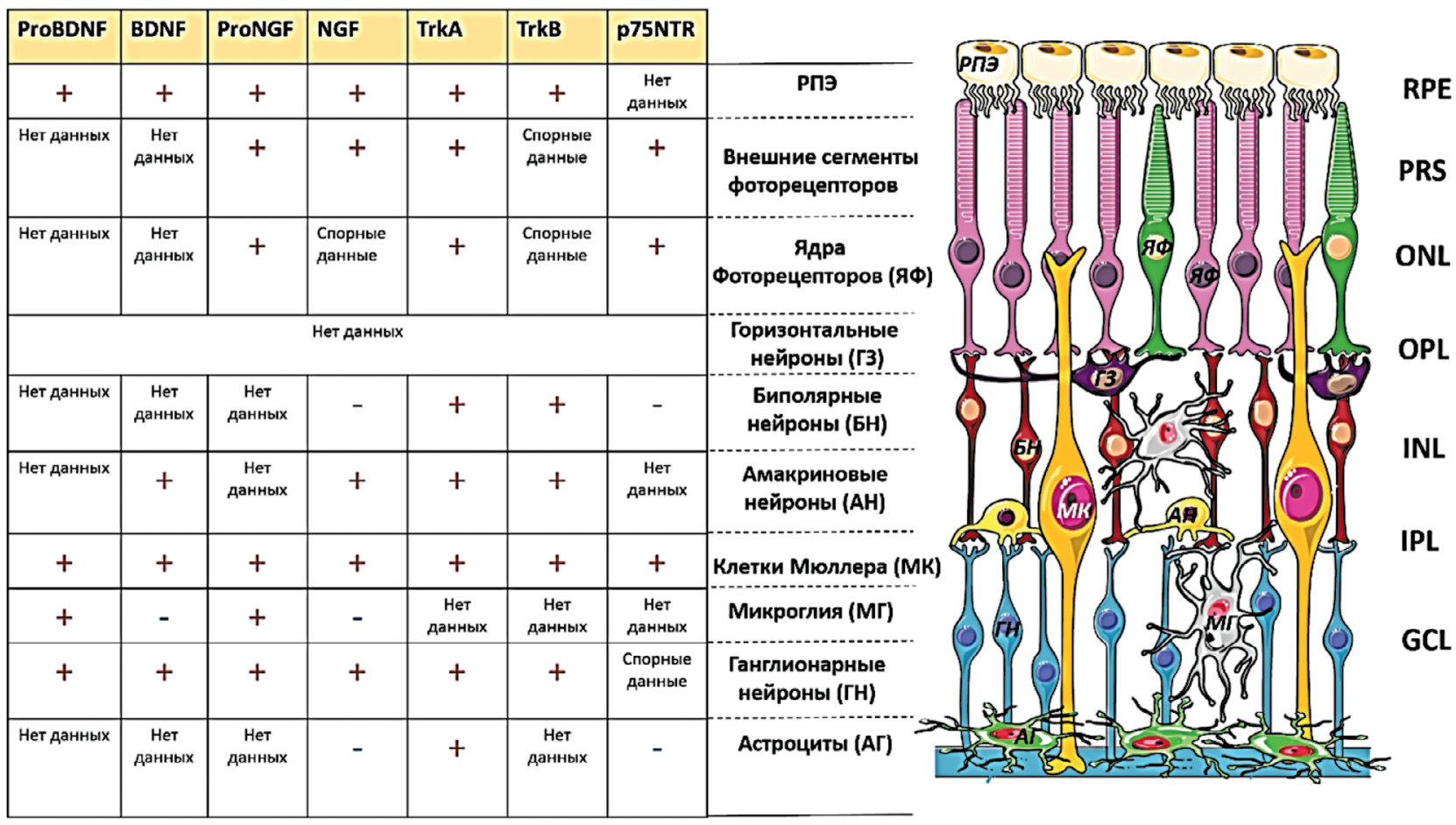

Рис. 1. Схематическое изображение слоёв сетчатки и локализации нейротрофических факторов в ней (составлено по [33]). Ганглионарный слой (GCL) содержит тела ганглионарных нейронов (ГH), генерирующие нервные импульсы; внутренний сетчатый слой (IPL) включает в себя аксоны биполярных клеток (БН), а также дендриты амакриновых (AH) и ганглионарных нейронов; внутренний ядерный слой (INL) содержит тела биполярных, амакриновых, горизонтальных (ГЗ) нейронов, а также клеток Mюллера (MK); внешний сетчатый слой (OPL) образован синапсами между аксонами фоторецепторов с дендритами биполярных клеток или аксонами и дендритами горизонтальных клеток; внешний ядерный слой (ONL) содержит тела фоторецепторов, а фотосенсорный слой (PRS) - их внешние фоточувствительные сегменты (палочки и колбочки); на границе с сосудистой оболочкой располагаются клетки ретинального пигментного эпителия (РПЭ). 
ротрофинов и зрелых нейротрофинов, а также их рецепторов усугубляется при развитии нейродегенеративных процессов в мозге. В частности, такие изменения выявлены в постмортальных образцах мозга людей с болезнью Альцгеймера [44]. Старение сетчатки, как в норме, так и при развитии ассоциированных со старением нейродегенеративных заболеваний (ВМД и глаукомы), также сопровождается нарушением нейротрофического обеспечения - наблюдается тенденция к смещению баланса пронейротрофины/зрелые нейротрофины в направлении преобладания проформ белков. При этом экспрессия Trk-рецепторов нейротрофинов снижается, а экспрессия $\mathrm{p} 75^{\mathrm{NTR}}$-рецептора повышается. Изменения в балансе как proNGF/зрелого NGF, так и экспрессии TrkA/p75NTR способствуют ретракции аксонов и нейрональному апоптозу - гибели клеток сетчатки [45, 46]. Недавно было показано, что в водянистой влаге пациентов, как с «влажной», так и с «сухой» формой ВМД, уровень BDNF снижен и, по данным когерентной оптической томографии, это снижение коррелирует с толщиной наружного слоя сетчатки. Такие результаты указывают на то, что низкий уровень BDNF может быть недостаточными для поддержания жизнеспособности фоторецепторов [47].

Следует подчеркнуть, что информация об изменениях нейротрофического обеспечения в сетчатке при развитии нейродегенеративных состояний получена в основном на различных экспериментальных моделях заболеваний сетчатки, таких как наследственный пигментный ретинит, отслоение сетчатки, глаукома и диабетическая ретинопатия. Показано, что при повреждении нейронов сетчатки происходит повышение уровня proNGF и уменьшение активности ферментов металлопротеиназ и плазмина, ответственных за внеклеточный процессинг proNGF. Недостаток в экспрессии металлопротеиназ снижает скорость превращения незрелой формы в mNGF и ускоряет темп нейронального апоптоза [33]. Повышенный уровень мPHK proNGF и NGF наблюдается в сетчатке мышей с индуцированной светом потерей фоторецепторов [33], а также у грызунов в моделях таких заболеваний сетчатки, как наследственный пигментный ретинит, отслоение сетчатки, глаукома и диабетическая ретинопатия. С нарушением нейротрофического обеспечения сетчатки - изменением экспрессии и локализации нейротрофических факторов - связано развитие аналогичной «сухой» ВМД у людей и ретинопатии у преждевременно стареющих крыс OXYS. В период прогрессии клинических признаков ВМД у них повышены содержание белка proBDNF и его колокализация с рецептором $\mathrm{p} 75^{\mathrm{NTR}}$ [48], что способствует усиленной гибели нейронов и фоторецепторов [49].

Значительные количества proNGF экспрессирует активированная микроглия, тем самым запуская апоптоз соседних клеток и способствуя нейродегенерации сетчатки. Исследования показали, что инъекции зрелой формы NGF предотвращают развитие подобного эффекта. При этом введение экзогенного NGF повышает выживаемость нейронов сетчатки также и за счёт повышения экспрессии других трофических факторов - BDNF, bFGF и TGF- $\beta$ [50]. NGF способен защищать клетки РПЭ от гибели в результате чрезмерного окислительного стресса, который является одной из причин развития ВМД [51]. Неинвазивный метод введения NGF в виде капель также оказался эффективным для предотвращения повреждения клеток сетчатки у животных моделей с глаукомой, а также пациентов, получавших терапию на основе капель с NGF [46, 52]. Установлено, что в форме глазных капель NGF также способен проявлять нейропротекторные свойства, защищая амакриновые клетки и фоторецепторы у людей с пигментным ретинитом, и у животных с моделями этого заболевания, что приводит к восстановлению у них зрительных функций $[53,54]$.

Способность BDNF защищать фоторецепторы на различных моделях дегенерации сетчатки была доказана еще в 1992 году. В экспериментах показано, что интравитеральные инъекции BDNF способны усилить выживаемость ганглионарных нейронов сетчатки при повреждении зрительного нерва. Введение BDNF крысам позволяет значительно увеличить процент клеток, не подвергнувшихся апоптозу [55], аналогичный эффект наблюдался и у кошек [56]. Генная терапия, направленная на повышение экспрессии BDNF, способна замедлять смерть ганглионарных клеток и потерю их аксонов в сетчатке мышей [57]. BDNF также способен увеличить количество дофаминергических амакриновых клеток, при этом он действует эффективней при совместном введении с другими нейротрофическими факторами - CNTF и GDNF [58].

При этом следует отметить, что несмотря на очевидную перспективность использования нейротрофинов в лечении ВМД, разработка использующих этот путь терапевтических средств затруднена в связи с отсутствием технологий, обеспечивающих надежную доставку в сетчатку и поддержание в ней эффективных терапевтических уровней нейротрофинов.

\section{Заключение}

Несмотря на интенсивные исследования патогенеза ВМД, имеющаяся информация об изменениях нейротрофического обеспечения сетчатки при старении и развитии ВМД ограничена. В то же время очевидно, что патогенез ВМД связан с характерными для старения нарушениями нейротрофического обеспечения сетчатки, которые усугубляются при развитии нейродегенративных процессов. Доказан нейропротекторный потенциал экзогенных нейротрофинов, однако для разработки эффективных препаратов на их основе необходимо решить вопрос о путях их эффективной доставки в сетчатку и поддержания в ней оптимального баланса нейротрофинов, определить который помогут дополнительные фундаментальные исследования. 


\section{Список литературы/References}

1. Wong W.L., Su X., Li X., Cheung C.M., Klein R., Cheng C.Y., Wong T.Y. Global prevalence of age-related macular degeneration and disease burden projection for 2020 and 2040: a systematic review and meta-analysis. Lancet Glob. Health. 2014; 2(2): 106-116. DOI: 10.1016/S2214-109X(13)70145-1

2. Harada C., Harada T., Quah H.M., Maekawa F., Yoshida K., Ohno S., Wada K., Parada L.F., Tanaka K. Potential role of glial cell line-derived neurotrophic factor receptors in Müller glial cells during light-induced retinal degeneration. Neuroscience. 2003; 122(1): 229235. DOI: 10.1016/S0306-4522(03)00599-2

3. Bothwell M. NGF, BDNF, NT3, and NT4. Handb. Exp. Pharmacol. 2014; 220: 3-15. DOI: 10.1007/978-3-642-45106-5_1

4. Holz F.G., Schmitz-Valckenberg S., Fleckenstein M. Recent developments in the treatment of age-related macular degeneration. $J$. Clin. Invest. 2014; 124(4): 1430-1438. DOI: 10.1172/JCI71029

5. Barben M., Samardzija M., Grimm C. The Role of Hypoxia, Hypoxia-Inducible Factor (HIF), and VEGF in Retinal Angiomatous Proliferation. Adv. Exp. Med. Biol. 2018; 1074: 177-183. DOI: 10.1007/978-3-319-75402-4_22

6. Narayanan R., Kuppermann B.D. Hot Topics in Dry AMD. Curr. Pharm. Des. 2017; 23(4): 542-546. DOI: 10.2174/1381612822666161 221154424

7. Miller J.W. Developing Therapies for Age-related Macular Degeneration: The Art and Science of Problem-solving: The 2018 Charles L. Schepens, MD, Lecture. Ophthalmol. Retina. 2019; 3(10): 900-909. DOI: $10.1016 /$ j.oret.2019.07.015

8. Hanus J., Zhao F., Wang S. Current therapeutic developments in atrophic age-related macular degeneration. Br. J. Ophthalmol. 2016; 100(1): 122-127. DOI: 10.1136/bjophthalmol-2015-306972

9. Luu J., Palczewski K. Human aging and disease: Lessons from age-related macular degeneration. Proc. Natl. Acad. Sci. USA. 2018; 115(12): 2866-2872. DOI: 10.1073 /pnas. 1721033115

10. Rudnitskaya E.A., Kolosova N.G., Stefanova N.A. Brain neurotrophic supply in ontogenesis and during development of neurodegenerative diseases. Moscow Univ. Biol. Sci. Bull. 2016; 71: 245. DOI: 10.3103/S009639251604009X

11. Wubben T.J., Zacks D.N., Besirli C.G. Retinal neuroprotection: current strategies and future directions. Curr. Opin. Ophthalmol. 2019; 30(3): 199-205. DOI: 10.1097/ICU.0000000000000558

12. Mitre M., Mariga A., Chao M.V. Neurotrophin signalling: novel insights into mechanisms and pathophysiology. Clin. Sci. (Lond). 2017; 131(1): 13-23. Review. DOI: 10.1042/CS20160044

13. Hauck S.M., Kinkl N., Deeg C.A., Swiatek-de Lange M., Schöffmann S., Ueffing M. GDNF family ligands trigger indirect neuroprotective signaling in retinal glial cells. Mol. Cell Biol. 2006; 26(7): 2746-2757. DOI: 10.1128/MCB.26.7.2746-2757.2006

14. Wen R., Tao W., Li Y., Sieving P.A. CNTF and retina. Prog. Retin. Eye Res. 2012; 31(2): 136-151. DOI: 10.1016/j.preteyeres. 2011.11.005

15. Pasquin S., Sharma M., Gauchat J.F. Ciliary neurotrophic factor (CNTF): New facets of an old molecule for treating neurodegenerative and metabolic syndrome pathologies. Cytokine Growth Factor Rev. 2015; 26(5): 507-515. DOI: 10.1016/j.cytogfr.2015.07.007

16. Harada C., Harada T., Quah H.M., Maekawa F., Yoshida K., Ohno S., Wada K., Parada L.F., Tanaka K. Potential role of glial cell line-derived neurotrophic factor receptors in Müller glial cells during light-induced retinal degeneration. Neuroscience. 2003; 122(1): 229235. DOI: 10.1016/S0306-4522(03)00599-2

17. Pramanik S., Sulistio Y.A., Heese K. Neurotrophin Signaling and Stem Cells-Implications for Neurodegenerative Diseases and Stem Cell Therapy. Mol. Neurobiol. 2017; 54(9): 7401-7459. DOI: 10.1007/ s12035-016-0214-7

18. Skaper S.D. Neurotrophic Factors: An Overview. Methods Mol. Biol. 2018; 1727: 1-17. DOI: 10.1007/978-1-4939-7571-6_1

19. Lewin G.R., Nykjaer A. Pro-neurotrophins, sortilin, and nociception. Eur. J. Neurosci. 2014; 39(3): 363-374. DOI: 10.1111/ejn.12466

20. Lu B., Nagappan G., Guan X., Nathan P.J., Wren P. BDNF-based synaptic repair as a disease-modifying strategy for neurodegenerative diseases. Nat. Rev. Neurosci. 2013; 14(6): 401-416. DOI: 10.1038/nrn3505

21. Deinhardt K., Chao M.V. Trk Receptors. In: Neurotrophic Factors / Ed. Lewin G.R., Carter B.D. Berlin, Heidelberg: Springer Berlin Heidelberg, 2014: 103-119. DOI: 10.1007/978-3-642-45106-5

22. Mitre M., Mariga A., Chao M.V. Neurotrophin signalling: novel insights into mechanisms and pathophysiology. Clin. Sci. (Lond). 2017; 131(1): 13-23. DOI: $10.1042 / C S 20160044$
23. Yu J.S., Cui W. Proliferation, survival and metabolism: the role of $\mathrm{PI} 3 \mathrm{~K} / \mathrm{AKT} / \mathrm{mTOR}$ signalling in pluripotency and cell fate determination. Development. 2016; 143(17): 3050-3060. DOI: 10.1242/ dev. 137075

24. Hackam A.S. Regulation of neurotrophin expression and activity in the retina. Adv. Exp. Med. Biol. 2008; 613: 343-349. DOI: 10.1007/978-0-387-74904-4_40

25. Leal G., Comprido D., Duarte C.B. BDNF-induced local protein synthesis and synaptic plasticity. Neuropharmacology. 2014; 76: 639656. DOI: $10.1016 /$ j.neuropharm. 2

26. Bothwell M. Recent advances in understanding context-dependent mechanisms controlling neurotrophin signaling and function. F1000Res. 2019; 8: F1000 Faculty Rev-1658. DOI: 10.12688/f1000research.19174.1

27. van Niekerk E.A., Tuszynski M.H., Lu P., Dulin J.N. Molecular and Cellular Mechanisms of Axonal Regeneration After Spinal Cord Injury. Mol. Cell Proteomics. 2016; 15(2): 394-408. DOI: 10.1074/mcp. R115.053751

28. Liu Y., Tao L., Fu X., Zhao Y., Xu X. BDNF protects retinal neurons from hyperglycemia through the TrkB/ERK/MAPK pathway. Mol. Med. Rep. 2013; 7(6): 1773-1778. DOI: 10.3892/mmr.2013.1433

29. Scholz-Starke J., Cesca F. Stepping Out of the Shade: Control of Neuronal Activity by the Scaffold Protein Kidins220/ARMS. Front Cell Neurosci. 2016; 10: 68. DOI: 10.3389/fncel.2016.00068

30. Kraemer B.R., Yoon S.O., Carter B.D. The biological functions and signaling mechanisms of the $\mathrm{p} 75$ neurotrophin receptor. Handb. Exp. Pharmacol. 2014; 220: 121-64. DOI: 10.1007/978-3-642-45106-5_6

31. Mitre M., Mariga A., Chao M.V. Neurotrophin signalling: novel insights into mechanisms and pathophysiology. Clin. Sci. (Lond). 2017; 131(1): 13-23. DOI: $10.1042 / C S 20160044$

32. Yang J., Harte-Hargrove L.C., Siao C.J., Marinic T., Clarke R., Ma Q., Jing D., Lafrancois J.J., Bath K.G., Mark W., Ballon D., Lee F.S., Scharfman H.E., Hempstead B.L. proBDNF negatively regulates neuronal remodeling, synaptic transmission, and synaptic plasticity in hippocampus. Cell Rep. 2014; 7(3): 796-806. DOI: 10.1016/j. celrep.2014.03.040

33. Garcia T.B., Hollborn M., Bringmann A. Expression and signaling of NGF in the healthy and injured retina. Cytokine Growth Factor Rev. 2017; 34: 43-57. DOI: 10.1016/j.cytogfr.2016.11.005

34. Balzamino B.O., Esposito G., Marino R., Keller F., Micera A. NGF Expression in Reelin-Deprived Retinal Cells: A Potential Neuroprotective Effect. Neuromolecular Med. 2015; 17(3): 314-25. DOI: $10.1007 / \mathrm{s} 12017-015-8360-\mathrm{z}$

35. Taylor S., Srinivasan B., Wordinger R.J., Roque R.S. Glutamate stimulates neurotrophin expression in cultured Müller cells. Brain Res. Mol. Brain Res. 2003; 111(1-2): 189-197. DOI: 10.1016/S0169328X(03)00030-5

36. Jansen P., Giehl K., Nyengaard J.R., Teng K., Lioubinski O., Sjoegaard S.S., Breiderhoff T., Gotthardt M., Lin F., Eilers A., Petersen C.M., Lewin G.R., Hempstead B.L., Willnow T.E., Nykjaer A. Roles for the pro-neurotrophin receptor sortilin in neuronal development, aging and brain injury. Nat. Neurosci. 2007; 10(11): 1449-1457. DOI: $10.1038 / \mathrm{nn} 2000$

37. Harada T., Harada C., Kohsaka S., Wada E., Yoshida K., Ohno S., Mamada H., Tanaka K., Parada L.F., Wada K. Microglia-Müller glia cell interactions control neurotrophic factor production during light-induced retinal degeneration. J. Neurosci. 2002; 22(21): 9228-9236.

38. Srinivasan B., Roque C.H., Hempstead B.L., Al-Ubaidi M.R., Roque R.S. Microglia-derived pronerve growth factor promotes photoreceptor cell death via p75 neurotrophin receptor. J. Biol. Chem. 2004; 279(40): 41839-41845. DOI: 10.1074/jbc.M402872200

39. Lu B., Nagappan G., Lu Y. BDNF and synaptic plasticity, cognitive function, and dysfunction. Handb Exp Pharmacol. 2014; 220: 223250. DOI: 10.1007/978-3-642-45106-5_9

40. Marmigère F., Carroll P. Neurotrophin signalling and transcription programmes interactions in the development of somatosensory neurons. Handb. Exp. Pharmacol. 2014; 220: 329-353. DOI: 10.1007/9783-642-45106-5 13

41. Bennett J.L., Zeiler S.R., Jones K.R. Patterned expression of BDNF and NT- 3 in the retina and anterior segment of the developing mammalian eye. Investig. Ophthalmol. Vis. Sci. 1999; 40(12): 2996-3005.

42. Vogler S., Hollborn M., Berk B.A., Pannicke T., Seeger J., Wiedemann P., Reichenbach A., Bringmann A. Ischemic regulation of brain-derived neurotrophic factor-mediated cell volume and TrkB expression in glial (Müller) and bipolar cells of the rat retina. Graef- 
es Arch. Clin. Exp Ophthalmol. 2016; 254(3): 497-503. DOI: 10.1007/ s00417-015-3250-5

43. Grishanin R.N., Yang H., Liu X., Donohue-Rolfe K., Nune G.C., Zang K., Xu B., Duncan J.L., Lavail M.M., Copenhagen D.R., Reichardt L.F. Retinal TrkB receptors regulate neural development in the inner, but not outer, retina. Mol. Cell Neurosci. 2008; 38(3): 431443. DOI: 10.1016/j.men.2008.04.004

44. Du Y., Wu H.T., Qin X.Y., Cao C., Liu Y., Cao Z.Z., Cheng Y. Postmortem Brain, Cerebrospinal Fluid, and Blood Neurotrophic Factor Levels in Alzheimer's Disease: A Systematic Review and Meta-Analysis. J. Mol. Neurosci. 2018; 65(3): 289-300. DOI: 10.1007/s12031018-1100-8

45. Espinet C., Gonzalo H., Fleitas C., Menal M.J., Egea J. Oxidative stress and neurodegenerative diseases: a neurotrophic approach. Curr. Drug Targets. 2015; 16(1): 20-30. DOI: 10.2174/1389450116666150107153233

46. Kimura A., Namekata K., Guo X., Harada C., Harada T. Neuroprotection, Growth Factors and BDNF-TrkB Signalling in Retinal Degeneration. Int. J. Mol. Sci. 2016; 17(9): pii: E1584. DOI: 10.3390/ ijms 17091584

47. Inanc Tekin M., Sekeroglu M.A., Demirtas C., Tekin K., Doguizi S., Bayraktar S., Yilmazbas P. Brain-Derived Neurotrophic Factor in Patients With Age-Related Macular Degeneration and Its Correlation With Retinal Layer Thicknesses. Invest. Ophthalmol. Vis. Sci. 2018; 59(7): 2833-2840. DOI: 10.1167/iovs. 18-24030.=

48. Telegina D.V., Kolosova N.G., Kozhevnikova O.S. Immunohistochemical localization of NGF, BDNF, and their receptors in a normal and AMD-like rat retina. BMC Med. Genomics. 2019; 12(Suppl 2): 48. DOI: $10.1186 / \mathrm{s} 12920-019-0493-8 .=$

49. Telegina D.V., Korbolina E.E., Ershov N.I., Kolosova N.G., Kozhevnikova O.S. Identification of functional networks associated with cell death in the retina of OXYS rats during the development of retinopathy. Cell Cycle. 2015; 14(22): 3544-3456. DOI: $10.1080 / 15384101.2015 .1080399$
50. Tirassa P., Rosso P., Iannitelli A. Ocular Nerve Growth Factor (NGF) and NGF Eye Drop Application as Paradigms to Investigate NGF Neuroprotective and Reparative Actions. Methods Mo.l Biol. 2018; 1727: 19-38. DOI: 10.1007/978-1-4939-7571-6_2

51. Mitra S., Behbahani H., Eriksdotter M. Innovative Therapy for Alzheimer's Disease-With Focus on Biodelivery of NGF. Front. Neurosci. 2019; 13: 38. DOI: 10.3389/fnins.2019.00038

52. Abed E., Corbo G., Falsini B. Neurotrophin family members as neuroprotectants in retinal degenerations. BioDrugs. 2015; 29(1): 1-13. DOI: $10.1007 / \mathrm{s} 40259-014-0110-5$

53. Rocco M.L., Balzamino B.O., Petrocchi Passeri P., Micera A., Aloe L. Effect of purified murine NGF on isolated photoreceptors of a rodent developing retinitis pigmentosa. PLoS One. 2015; 10(4): e0124810. DOI: 10.1371/journal.pone.0124810

54. Falsini B., Iarossi G., Chiaretti A., Ruggiero A., Manni L., Galli-Resta L., Corbo G., Abed E. NGF eye-drops topical administration in patients with retinitis pigmentosa, a pilot study. J. Transl. Med. 2016; 14: 8. DOI: 10.1186/s12967-015-0750-3

55. Daly C., Ward R., Reynolds A.L., Galvin O., Collery R.F., Kennedy B.N. Brain-Derived Neurotrophic Factor as a Treatment Option for Retinal Degeneration. Adv. Exp. Med. Biol. 2018; 1074: 465-471. DOI: 10.1007/978-3-319-75402-4_57

56. Weber A.J., Harman C.D. BDNF treatment and extended recovery from optic nerve trauma in the cat. Investig. Ophthalmol. Vis. Sci. 2013; 54(10): 6594-6604. DOI: 10.1167/iovs.13-12683

57. Feng L., Puyang Z., Chen H., Liang P., Troy J.B., Liu X. Overexpression of Brain-Derived Neurotrophic Factor Protects Large Retinal Ganglion Cells After Optic Nerve Crush in Mice. eNeuro. 2017; 4(1): ENEURO.0331-16.2016. DOI: 10.1523/ENEURO.0331-16.2016

58. Afarid M., Torabi-Nami M., Zare B. Neuroprotective and restorative effects of the brain-derived neurotrophic factor in retinal diseases. J. Neurol. Sci. 2016; 363: 43-50. DOI: 10.1016/j.jns.2016.02.024

\section{Сведения об авторах:}

Телегина Дарья Викторовна - кандидат биологических наук, научный сотрудник лаборатории молекулярных механизмов старения Федерального государственного бюджетного научного учреждения «Федеральный исследовательский центр Институт цитологии и генетики Сибирского отделения Российской академии наук»; http://orcid.org/0000-0001-8096-0519

Кожевникова Оюна Суранзановна - кандидат биологических наук, старший научный сотрудник лаборатории молекулярных механизмов старения Федерального государственного бюджетного научного учреждения «Федеральный исследовательский центр Институт цитологии и генетики Сибирского отделения Российской академии наук»; http://orcid.org/0000-0001-6475-4061

Колосова Наталия Гориславовна - доктор биологических наук, профессор, заведующая лабораторией молекулярных механизмов старения Федерального государственного бюджетного научного учреждения «Федеральный исследовательский центр Институт цитологии и генетики Сибирского отделения Российской академии наук»; http://orcid.org/0000-0003-2398-8544 